\title{
Superior Sagittal Sinus Invasion by Malignant Glioma: Case Report and Literature Review
}

\section{Invasão do seio sagital superior por glioma maligno: Relato de caso e revisão da literatura}

\author{
Gonçalo Cerdeira Figueiredo ${ }^{1}$ Sérgio Moreira ${ }^{1}$ Célia Pinheiro ${ }^{1}$ Alfredo Calheiros ${ }^{1}$ \\ ${ }^{1}$ Department of Neurosurgery, Centro Hospitalar do Porto, Porto, \\ Portugal \\ Arq Bras Neurocir 2019;38:47-50.

\begin{abstract}
Address for correspondence Gonçalo Cerdeira Figueiredo, MD, Department of Neurosurgery, Centro Hospitalar do Porto, Largo Prof. Abel Salazar, 4099-001, Porto, Portugal
\end{abstract} \\ (e-mail: gfigueiredo03@gmail.com).
}

\section{Abstract \\ Keywords \\ - anaplastic oligodendroglioma \\ - superior sagittal sinus}

\section{Resumo}

\section{Palavras-chave}

- oligodendroglioma anaplásico

- seio sagital superior
Anaplastic oligodendrogliomas (AOs) correspond to $\sim 23 \%$ of all oligodendrogliomas. They correspond to a tumor with malignant histological characteristics, focal or diffuse, associated with a worse prognosis. In the present case report, we describe the case of a 30-year-old female submitted to resection of a right parietal lesion whose histology showed to be an AO. She underwent complementary treatment with chemotherapy and radiotherapy according to the Roger Stupp protocol. Four years after the initial diagnosis, there was tumor recurrence within the superior sagittal sinus, with no evidence of recurrence elsewhere. In the literature, we have found no similar published case reinforcing the rarity of this condition

Oligodendrogliomas anaplásicos correspondem a $\sim 23 \%$ de todos os oligodendrogliomas. Eles correspondem a um tumor com características histológicas malignas, focais ou difusas, associadas a um pior prognóstico. Descrevemos aqui o caso de uma mulher de 30 anos de idade submetida à ressecção de uma lesão parietal direita, cuja histologia mostrou ser um oligodendroglioma anaplásico. A paciente foi submetida a tratamento complementar com quimioterapia e radioterapia de acordo com o protocolo de Roger Stupp. Quatro anos após o diagnóstico inicial, ocorreu recidiva tumoral no seio sagital superior, sem evidência de recorrência em outro local. Na literatura, não encontramos nenhum caso semelhante publicado reforçando a raridade desta condição.

\section{Introduction}

Oligodendrogliomas represent the $3^{\text {rd }}$ most common type of glial tumors, corresponding to between $\sim 4$ and $15 \%$ of all gliomas of the central nervous system (CNS). ${ }^{1}$

Anaplastic oligodendrogliomas (AOs) (World Health Organization [WHO] grade III) ${ }^{2}$ correspond to $\sim 23 \%$ of all oligodendrogliomas. ${ }^{3}$ They correspond to a tumor with malignant histological characteristics, focal or diffuse, associated with a worse prognosis, ${ }^{1}$ in comparison to the oligodendrogliomas WHO grade II. ${ }^{2}$ Anaplastic oligodendrogliomas are associated with a 5 - and 10 -year average survival rate of $63 \%$ and $33 \%$, respectively. ${ }^{4}$

In the present case report, we describe the case of an $\mathrm{AO}$ with a pattern of tumor dissemination not described in the literature, into the superior sagittal sinus (SSS), with its consequent obliteration, in a patient with no evidence of tumor recurrence elsewhere. received

October 27, 2018

accepted

January 8, 2019

published online

February 8, 2019
DOI https://doi.org/

10.1055/s-0039-1678587. ISSN 0103-5355.
Copyright $\odot 2019$ by Thieme Revinter

Publicações Ltda, Rio de Janeiro, Brazil
License terms

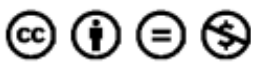




\section{Case Report}

A 30-year-old woman presented with an inaugural seizure in 2013. She was submitted to a computed tomography (CT) of the brain that revealed a right parietal corticosubcortical lesion, with calcifications (-Fig. 1), and to a magnetic resonance imaging (MRI) of the brain that revealed a hypointense lesion in the $\mathrm{T} 1$ weights with areas of contrast enhancement (-Fig. 2) suggesting a high-grade glioma. The patient underwent a surgical excision with gross total resection (GTR) of the lesion. In the postoperative period, she developed a left hemisphere apraxia and a left inferior quadrantanopsia.

The neuropathological study showed a highly cellular glial tumor, with diffuse invasion of the cerebral parenchyma, composed of cells of relatively uniform round nuclei and with frequent perinuclear halos (-Fig. 3). Necrosis, frequent mitoses, and a moderate proliferation index were also observed. The immunohistochemistry study was positive for glial fibrillary acidic protein (GFAP), and the tumor was isocitrate dehydrogenase (IDH-1) and $\alpha$ thalassemia/mental retardation syndrome X-linked (ATRX) positive. Based on these characteristics, the diagnosis was AO (World Health Organization grade $\mathrm{III}^{2}$ ).

The complementary treatment was started according to the Roger Stupp protocol. The patient completed 30 sessions of radiotherapy $(2 \mathrm{~Gy} / \mathrm{session}$, in a total of $60 \mathrm{~Gy})$, with concomitant temozolomide $75 \mathrm{mg} / \mathrm{m}^{2}$ for 7 days per week, for 6 weeks. After that, she underwent 6 cycles of adjuvant temozolomide $150 \mathrm{mg} / \mathrm{m}^{2}$ for 5 days per month.

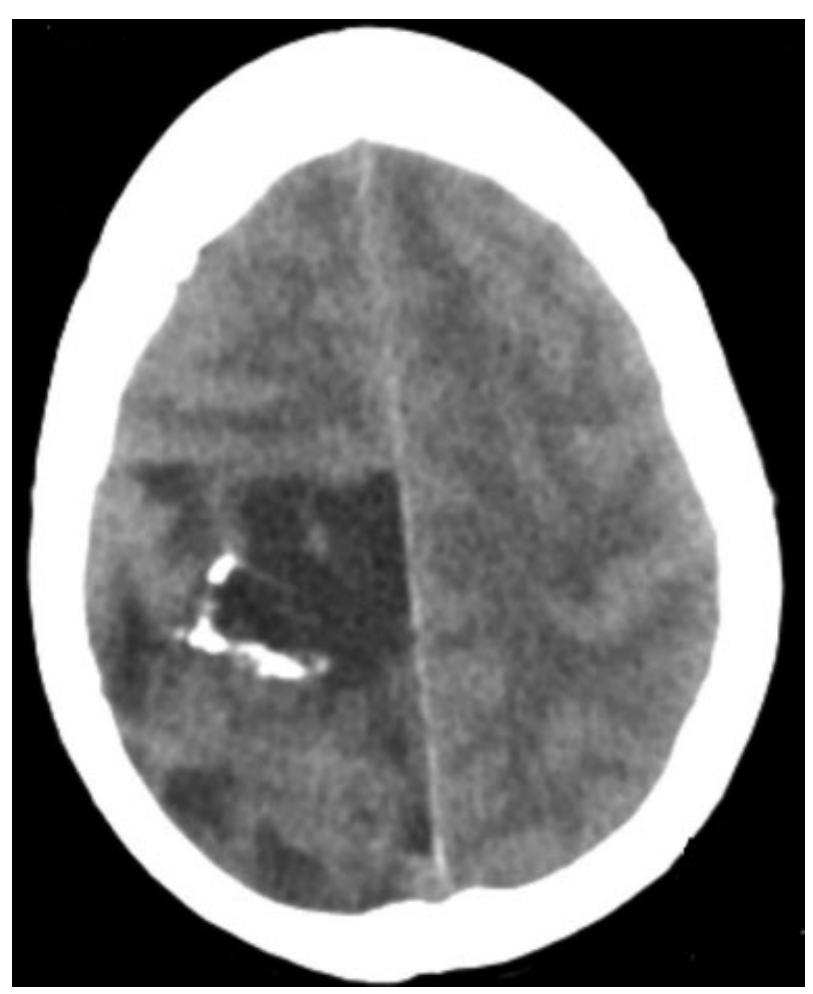

Fig. 1 Computed tomography scan showing a right parietal lesion with calcification.

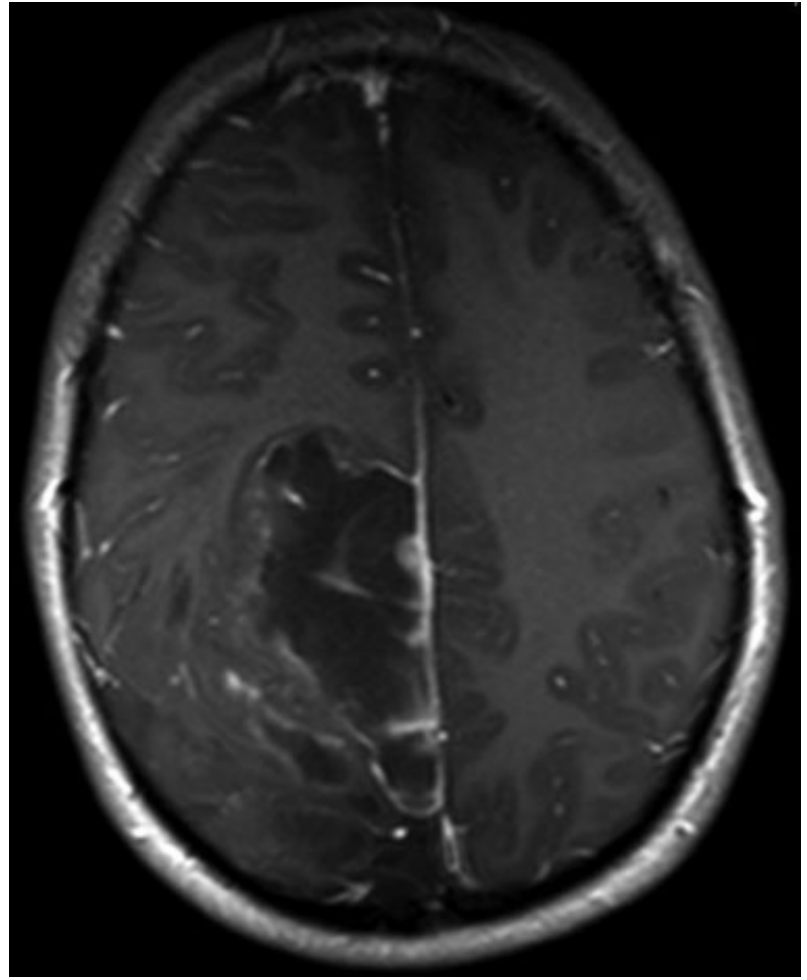

Fig. 2 Axial T1-weighted magnetic resonance imaging showing a hypointense right parietal lesion with areas of contrast enhancement.

Four years after the initial diagnosis in an imaging control by MRI, a recurrence of the tumor was observed, located within the SSS in the middle and posterior third, with no recurrence elsewhere, particularly in the surgical site (-Fig. 4). Considering the hypothesis of surgical reintervention, an angiography was performed, which confirmed the absence of blood flow in the invaded portion of the SSS (-Fig. 5).

The patient was submitted to a new surgical intervention with en bloc resection of the occluded SSS, and it was verified intraoperatively that the external walls of the sinus were not invaded by the tumor and had a cortical vein that drained to

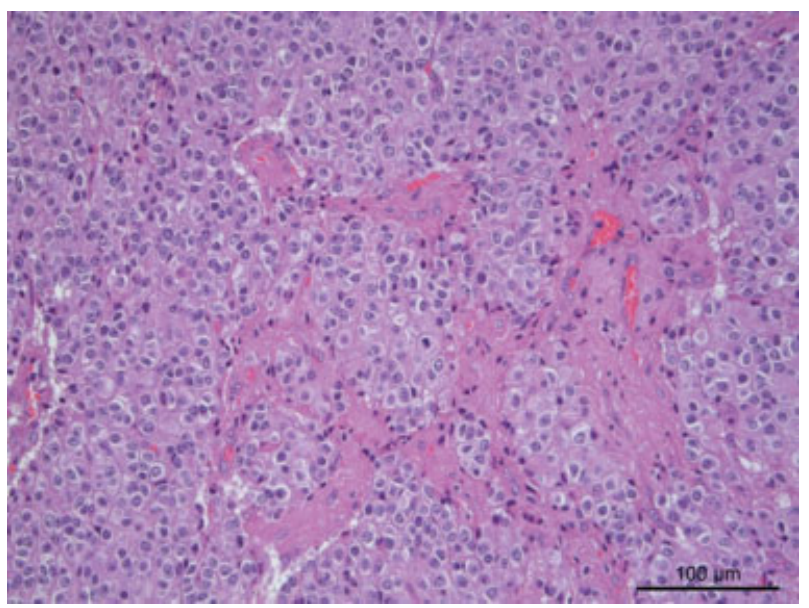

Fig. 3 Hematoxylin and eosin staining showing a hypercellular tumor with round nuclei with a perinuclear halo, with frequent mitoses. 


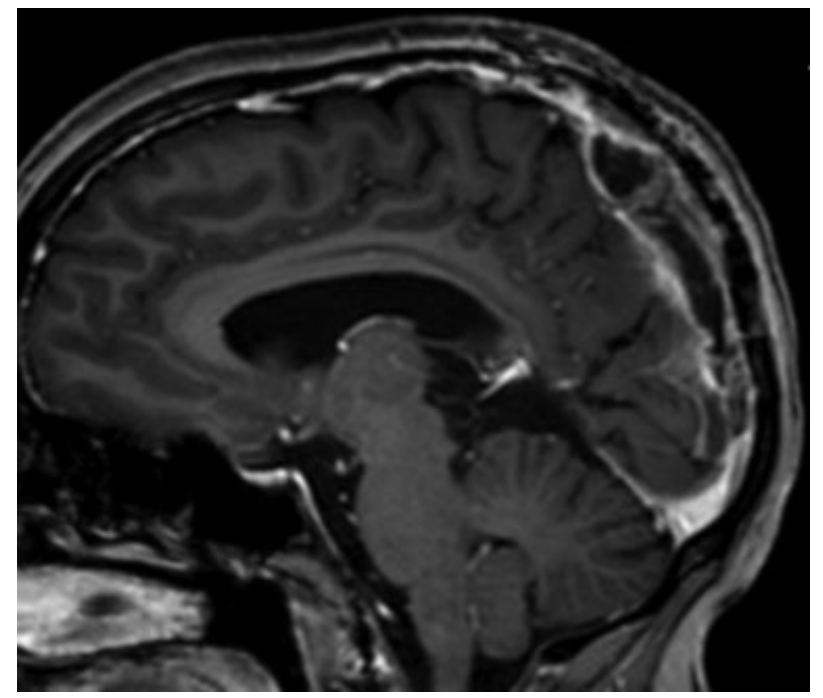

Fig. 4 Sagittal T1-weighted magnetic resonance imaging with contrast showing tumor recurrence located within the superior sagittal sinus in the middle and posterior third.

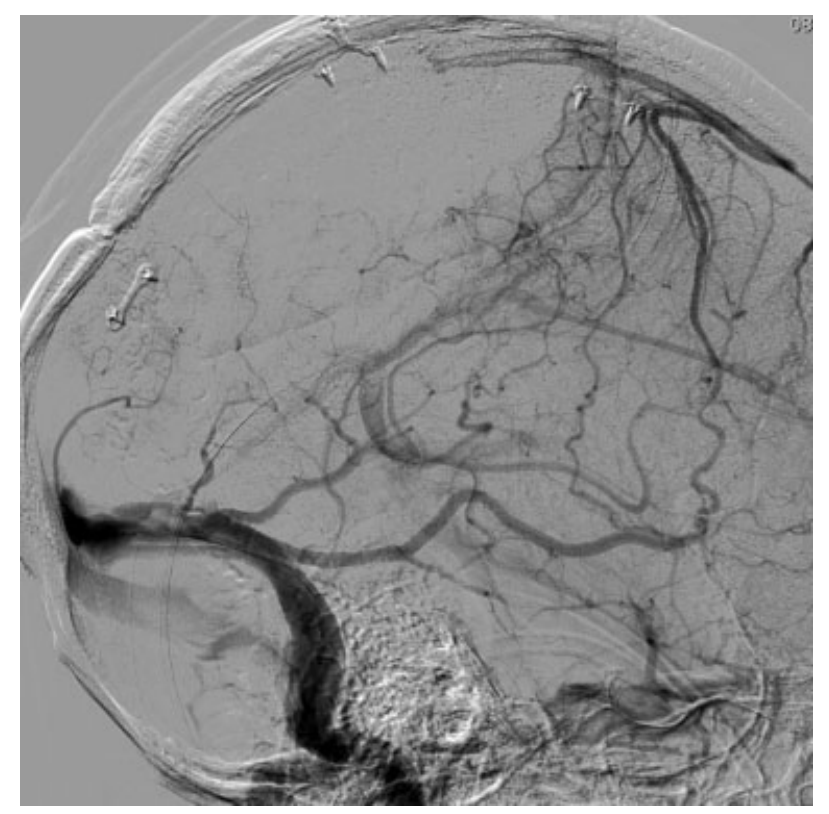

Fig. 5 Angiography with absence of flow in the middle and posterior third of the superior sagittal sinus.

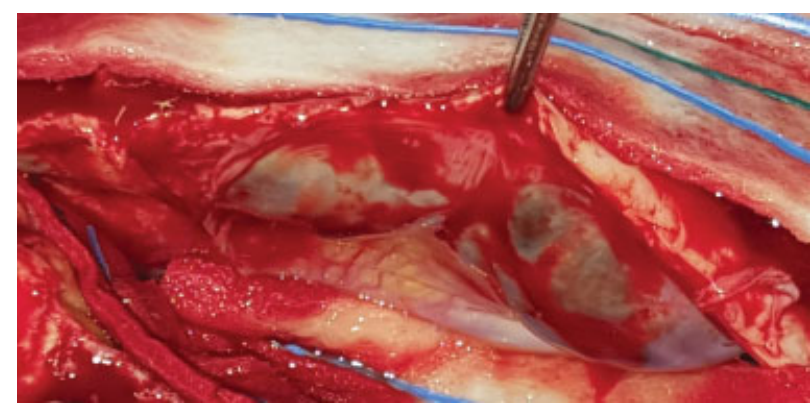

Fig. 6 Intraoperative images showing the sinus walls macroscopically without tumor invasion and a cortical drainage vein in the direction of the occluded superior sagittal sinus.

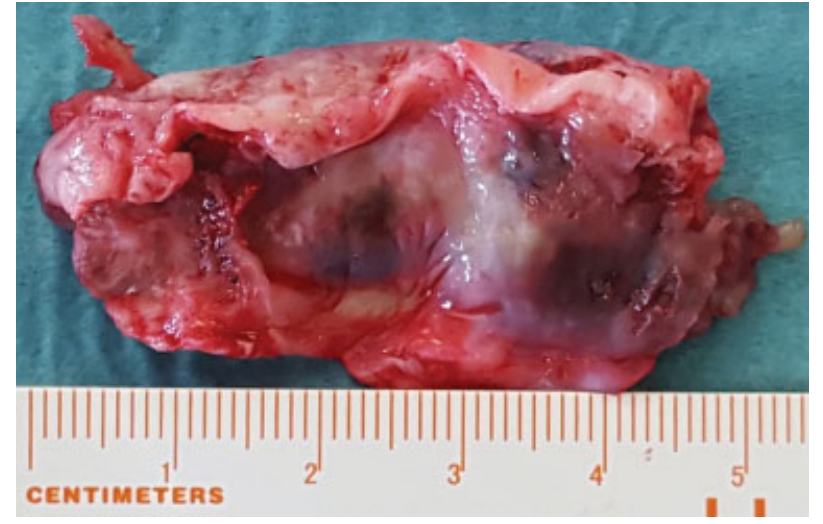

Fig. 7 En bloc resection of the tumor.

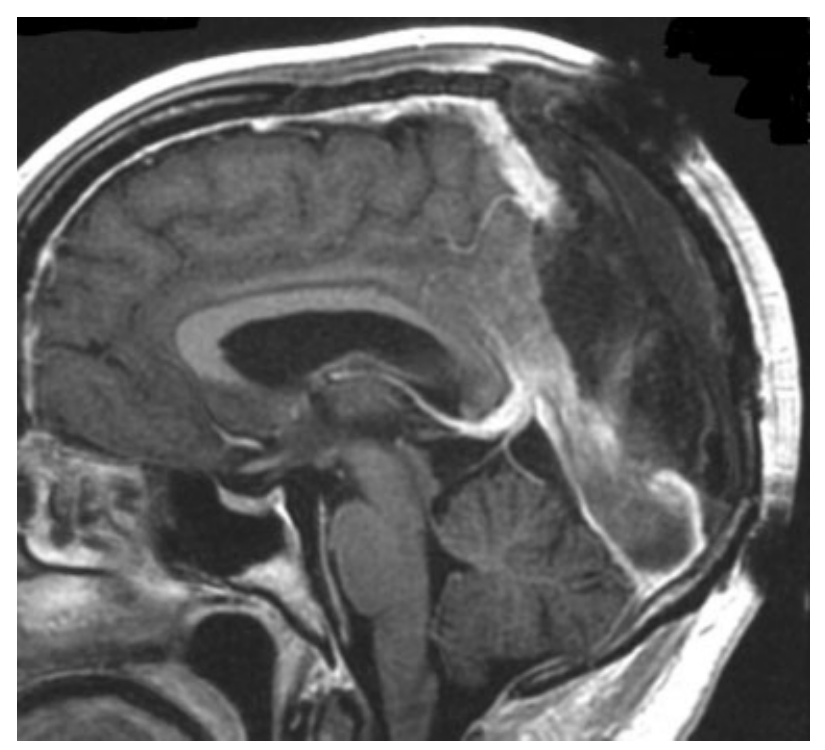

Fig. 8 Second surgery postoperative sagittal T1-weighted magnetic resonance imaging showing the resection of the occluded sinus.

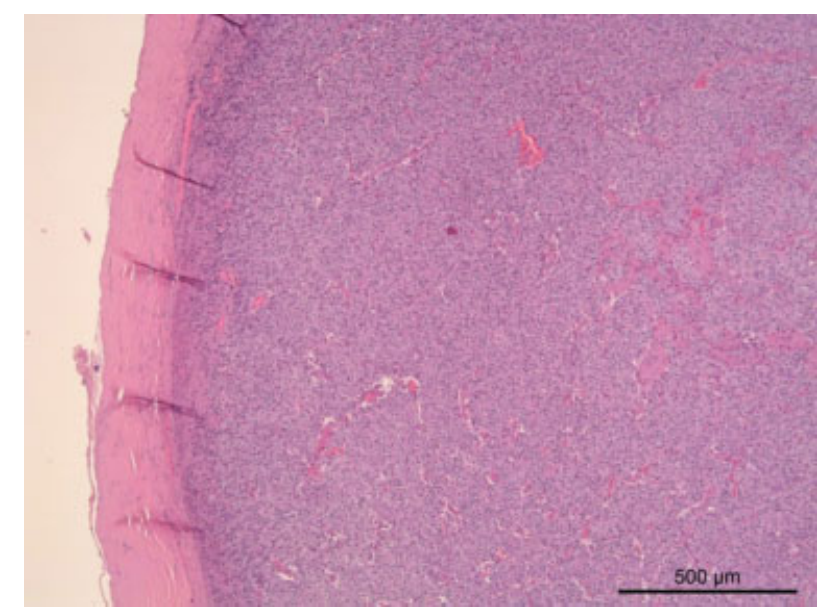

Fig. 9 Hematoxylin and eosin staining showing a hypercellular tumor, but no invasion of the sinus wall by malignant cells. 
the occluded portion of the SSS ( - Figs. 6 and 7). A postoperative MRI was performed, which showed the total removal of the invaded portion of the sinus ( $\mathbf{- F i g . ~ 8 ) . ~ T h e ~ n e u r o p a t h o - ~}$ logical study showed a tumor with the same characteristics as the previous tumor, and the walls of the sinus were not invaded by the tumor (-Fig. 9).

Currently, the patient presents 5 years of global survival, with status 1 in the Eastern Cooperative Oncology Group (ECOG) Scale of Performance Status.

\section{Discussion}

Oncological diseases are often associated with hypercoagulable states due to the prothrombotic properties of neoplastic cells. ${ }^{1}$ Malignant tumors of the CNS, mainly gliomas, are associated with deep venous thrombosis and pulmonary thromboembolism. ${ }^{1,5}$ Several cases of venous sinus thrombosis associated with malignant CNS tumors and complementary treatments have been described in the literature. ${ }^{6}$

The case described in the present report refers to a tumor that spread to the interior of a cerebral venous sinus, without continuity spread, since the outer wall of the sinus was not invaded and there was no evidence of disease progression elsewhere, particularly in the surgical site. From the research done in the PubMed and Google Scholar databases, we have found no registered case of exclusive dissemination to the venous sinuses of a glial tumor.

We believe that because glial tumors are an oncology pathology, a state of hypercoagulability may have occurred, which in turn has caused a decrease in the SSS drainage flow. This fact created favorable conditions for the tumor cells to spread to the interior of the sinus through cortical veins and to find conditions to fix in and metastasize to the SSS.

\section{Conclusion}

Although no case is described in the literature, glial tumors can spread into the venous sinuses without further progression of the disease, as we have described in the present case.

In the case of absence of blood flow of the venous sinuses, in the context of CNS oncological pathology, we must always take into account in the differential diagnosis the possibility of obstruction caused by tumor invasion, especially in glial tumors.

\section{Conflicts of Interests}

The authors have no conflicts of interests to declare.

\section{References}

1 Simonetti G, Gaviani P, Botturi A, Innocenti A, Lamperti E, Silvani A. Clinical management of grade III oligodendroglioma. Cancer Manag Res 2015;7:213-223

2 Louis DN, Ohgaki H, Wiestler OD, Cavenee WK. (2016) World Health Organization Histological Classification of Tumours of the Central Nervous System. France: International Agency for Research on Cancer

3 Central Brain Tumor Registry of the United States. Primary brain tumors in the United States. Statistical report. 1992-1997. 2000. Chicago, IL: Published by the Central Brain Tumor Registry of the United States

4 Henderson KH, Shaw EG. Randomized trials of radiation therapy in adult low-grade gliomas. Semin Radiat Oncol 2001;11(02): 145-151

5 Rogers LR. Cerebrovascular complications in cancer patients. Neurol Clin 2003;21(01):167-192

6 Vargo JA, Snelling BM, Ghareeb ER, et al. Dural venous sinus thrombosis in anaplastic astrocytoma following concurrent temozolomide and focal brain radiotherapy plus bevacizumab. J Neurooncol 2011;104(02):595-598 